\title{
ARTICLE Medial PFC AMPA receptor and BDNF signaling are required for the rapid and sustained antidepressant-like effects of $5-\mathrm{HT}_{1 \mathrm{~A}}$ receptor stimulation
}

\author{
Kenichi Fukumoto ${ }^{1,2}$, Manoela V. Fogaça ${ }^{1}$, Rong-Jian Liu ${ }^{1}$, Catharine H. Duman ${ }^{1}$, Xiao-Yuan Li ${ }^{1}$, Shigeyuki Chaki ${ }^{2}$ and \\ Ronald S. Duman (iD)
}

\begin{abstract}
We previously reported that the serotonergic system is important for the antidepressant-like effects of ketamine, a non-competitive $\mathrm{N}$-methyl-D-aspartate receptor antagonist, which produces rapid and long-lasting antidepressant effects in patients with major depressive disorder (MDD). In particular, selective stimulation of the $5-\mathrm{HT}_{1 \mathrm{~A}}$ receptor in the medial prefrontal cortex (mPFC), as opposed to the somatic 5- $\mathrm{HT}_{1 \mathrm{~A}}$ autoreceptor, has been shown to play a critical role in the antidepressant-like actions of ketamine. However, the detailed mechanisms underlying mPFC 5- $\mathrm{HT}_{1 \mathrm{~A}}$ receptor-mediated antidepressant-like effects are not fully understood. Here we examined the involvement of the glutamate AMPA receptor and brain-derived neurotrophic factor (BDNF) in the antidepressant-like effects of 5- $\mathrm{HT}_{1 \mathrm{~A}}$ receptor activation in the MPFC. The results show that intra-mPFC infusion of the 5-HT $1 \mathrm{~A}$ receptor agonist 8-OH-DPAT induces rapid and long-lasting antidepressant-like effects in the forced swim, novelty-suppressed feeding, female urine sniffing, and chronic unpredictable stress tests. In addition, the results demonstrate that the antidepressantlike effects of intra-mPFC infusion of 8-OH-DPAT are blocked by co-infusion of an AMPA receptor antagonist or an anti-BDNF neutralizing antibody. In addition, mPFC infusion of 8-OH-DPAT increased the phosphorylation of signaling proteins downstream of BDNF, including mTOR, ERK, 4EBP1, and p70S6K. Finally, selective stimulation of the 5-HT $1 \mathrm{~A}$ receptor increased levels of synaptic proteins and synaptic function in the $\mathrm{MPFC}$. Collectively, these results indicate that selective stimulation of $5-\mathrm{HT}_{1 \mathrm{~A}}$ receptor in the mPFC exerts rapid and sustained antidepressant-like effects via activation of AMPA receptor/BDNF/mTOR signaling in mice, which subsequently increase synaptic function in the $\mathrm{MPFC}$, and provide evidence for the $5-\mathrm{HT}_{1 \mathrm{~A}}$ receptor as a target for the treatment of MDD.
\end{abstract}

Neuropsychopharmacology (2020) 45:1725-1734; https://doi.org/10.1038/s41386-020-0705-0

\section{INTRODUCTION}

Major depressive disorder (MDD) is a global health problem associated with a significant social and economic burden, with an estimated lifetime prevalence in the USA of $~ 17 \%[1,2]$. Although the majority of individuals with depression (about 65\%) exhibit some improvement with currently available antidepressant medications, it can take weeks to months for a therapeutic response, and more than $30 \%$ of patients remain resistant to these agents [3]. These findings highlight the need for development of new antidepressants with faster onset of action and greater efficacy.

The glutamatergic system has gathered great attention as an attractive target for the development of novel antidepressants. The most notable example is ketamine, a non-competitive $N$ methyl-D-aspartate (NMDA) receptor antagonist, that has been reported to exert rapid and long-lasting antidepressant as well as anti-suicidal effects in patients with MDD, including those considered to have treatment-resistant depression (TRD) [4-8]. However, ketamine produces undesirable side effects, notably psychotomimetic and dissociative symptoms and has abuse potential [9]. Therefore, novel antidepressants with ketamine-like rapid and efficacious actions, but without the side effects, are a major focus of current drug development.

Previous studies have demonstrated that the antidepressantlike effects of ketamine required a-amino-3-hydroxy-5-methyl-4isoxazole propionate (AMPA) receptor and activity-dependent release of brain-derived neurotrophic factor (BDNF), followed by activation of the mechanistic target of rapamycin complex-1 (mTORC1) signaling in the medial prefrontal cortex (mPFC) [10-13]. In addition to these mechanisms, recent studies demonstrate that the serotonergic system plays a critical role in the antidepressant-like effects of ketamine. Ketamine increases extracellular serotonin (5-HT) levels in the MPFC, and this increase is mediated by AMPA receptor activation $[14,15]$. Moreover, the antidepressant-like actions of ketamine are blocked by pretreatment with a 5-HT-depleting agent [16-19], and by intra-mPFC infusion of a $5-\mathrm{HT}_{1 \mathrm{~A}}$ receptor antagonist, WAY100635 $[17,20]$. These findings indicate that the postsynaptic $5-\mathrm{HT}_{1 \mathrm{~A}}$ receptor in the mPFC, which is activated by AMPA receptor-dependent 5-HT release, is involved in the antidepressant-like effects of ketamine.

We have also demonstrated that intra-mPFC infusion but not systemic administration of $8-\mathrm{OH}-\mathrm{DPAT}$, a $5-\mathrm{HT}_{1 \mathrm{~A}}$ receptor agonist

\footnotetext{
${ }^{1}$ Departments of Psychiatry and Neurosciences, Yale University School of Medicine, 34 Park Street, New Haven, CT 06520, USA and ${ }^{2}$ Research Headquarters, Taisho Pharmaceutical Co., Ltd., 1-403 Yoshino-cho, Kita-ku, Saitama, Saitama 331-9530, Japan

Correspondence: Kenichi Fukumoto (kenichi-fukumoto@ds-pharma.co.jp)
}

Received: 8 December 2019 Revised: 26 April 2020 Accepted: 5 May 2020

Published online: 12 May 2020 


\section{6}

with 60 -fold selectivity for the $5-\mathrm{HT}_{1 \mathrm{~A}}$ receptor over other $5-\mathrm{HT}$ receptor subtypes, and even greater selectivity relative to other classes of monoamine receptors [21], induces rapid and sustained antidepressant-like effects, lasting up to $24 \mathrm{~h}$ after administration [20]. Combined with evidence that WAY100635 blocks the effects of ketamine, the results indicate that selective of $5-\mathrm{HT}_{1 \mathrm{~A}}$ receptor stimulation in the mPFC contributes to the antidepressant-like effects of ketamine [20]. Furthermore, we previously demonstrated that phosphoinositide-3 kinase (PI3K)/Akt and mTORC1 signaling mediate the antidepressant-like effects of 5$\mathrm{HT}_{1 \mathrm{~A}}$ receptor stimulation, providing evidence for a role of synaptic plasticity $[11,20,22]$. Therefore, selective $5-\mathrm{HT}_{1 \mathrm{~A}}$ receptor stimulation in the mPFC, as opposed to the somatic $5-\mathrm{HT}_{1 \mathrm{~A}}$ autoreceptor, may be a potential target for developing novel, rapid-acting ketamine-like antidepressants. This is also consistent with reports that biased agonists with greater affinity for cortical $5-\mathrm{HT}_{1 \mathrm{~A}}$ heteroreceptor produce antidepressant-like actions $[23,24]$. However, the detailed antidepressant-like actions and underlying mechanisms of postsynaptic $5-\mathrm{HT}_{1 \mathrm{~A}}$ receptor stimulation in the MPFC remain to be fully investigated.

In the current study we first examine the antidepressant-like profile of infusing a $5-\mathrm{HT}_{1 \mathrm{~A}}$ receptor agonist into the mPFC in several behavioral tests. This includes a chronic unpredictable stress (CUS) model, which provides a rigorous test of the rapid and sustained antidepressant-like actions of $5-\mathrm{HT}_{1 \mathrm{~A}}$ receptor stimulation. In addition, we examine the role of AMPA receptor/BDNF/ mTORC1 signaling and synaptic function, which are critical for the actions of ketamine [10-13] in the antidepressant-like actions of mPFC $5-\mathrm{HT}_{1 \mathrm{~A}}$ receptor stimulation.

\section{MATERIALS AND METHODS}

Animals and drug administration

Ten- to thirteen-week-old male C57BL/6J mice (Jackson Laboratories) were used. Animals were housed and maintained in standard conditions with a 12-h light/dark cycle and ad libitum food and water unless otherwise noted. ( \pm )8-hydroxy-2-(di-npropylamino)tetralin (8-OH-DPAT; Abcam, Cambridge, MA, USA) was dissolved in saline and administered subcutaneously (s.c.) for systemic administration. Animal use and procedures were in accordance with the National Institutes of Health guidelines and approved by the Yale University Animal Care and Use Committees.

\section{Surgical and infusion procedures}

Bilateral 26-gauge guide cannulae (Plastics One) were implanted with the cannulae tips $0.3 \mathrm{~mm}$ above the infusion sites in the $\mathrm{mPFC}$ (anteroposterior, $1.8 \mathrm{~mm}$ from bregma; lateral, $\pm 0.4 \mathrm{~mm}$; ventral, $-2.5 \mathrm{~mm}$ ) as previously described [25]. Mice were bilaterally infused with the following agents depending on the experiment: $8-\mathrm{OH}-\mathrm{DPAT}$ ( 1 and $3 \mathrm{nmol} / \mathrm{side}), \mathrm{NBQX}(0.03 \mathrm{nmol} /$ side; Tocris Bioscience, Minneapolis, MN, USA), saline (vehicle for 8-OH-DPAT and NBQX), a function-blocking anti-BDNF neutralizing antibody (nAB) $(0.2 \mu \mathrm{g} / \mathrm{side}$, EMD Millipore, Billerica, MA, USA) or sheep IgG (vehicle for function-blocking anti-BDNF $n A B$ ) for 2 min at a rate of $0.1 \mu \mathrm{L} / \mathrm{min}$ (total volume is $0.2 \mu \mathrm{L}$ ). The dose and timing of each compound administration are based on previous reports $[18,20,25]$.

\section{Behavior studies}

The forced swimming test (FST), locomotor activity test (LMA), novelty-suppressed feeding test (NSFT), and female urine sniffing test (FUST) were carried out as previously described [25]. For naive mice, we used FUST to detect rewarding activity, and we demonstrated that ketamine exerted the antidepressant-like effect in this test [25]. In FST, each animal was placed in the swim cylinders for a $10 \mathrm{~min}$ period and videotaped. Data were analyzed by scoring the immobility time by an experimenter blinded to the treatment groups. In LMA, each animal was placed individually in clean cages for $30 \mathrm{~min}$, during which time the number of beam breaks was measured using the Med-PC software (Med Associates, St Albans, VT). In NSFT, animals were food-deprived overnight and placed in an open field with a small amount of food in the center. The latency to feed was measured with a cut-off time of $15 \mathrm{~min}$ in a blind manner. Then, the amount of food consumption in home cages for $10 \mathrm{~min}$ was measured to verify motivation to feed. In FUST, each animal was exposed to a cotton-tipped applicator infused with water or fresh urine from females of the same strain for $5 \mathrm{~min}$ and the time spent sniffing the cotton-tipped applicator was measured by a blinded experimenter. Prior studies have reported that the estrous cycle has no effect on the preference of males for female odors [26]. Time spent biting the cotton-tip was excluded from the recording time. For FST, NSFT, and FUST, the experimenter was blinded to the treatments.

\section{Chronic unpredictable stress}

CUS was performed as previously described [27]. Mice were exposed to random intermittent stressors over 14 days, 2 times per day, including cage rotation, isolation, static white noise, food or water deprivation, light on overnight, light off during the day, rat odor, stroboscope overnight, crowding, wet bedding, no bedding, forced swimming, restraint and tilted cage. To measure anhedonia induced by CUS, a sucrose consumption test (SCT) was performed. Briefly, animals were habituated for $24 \mathrm{~h}$ to $1 \%$ sucrose; following a 12-h deprivation period, amount of sucrose consumed was determined for $1 \mathrm{~h}$.

\section{Western blot}

The phosphorylation level of ERK, 4EBP1, mTOR, and p70S6K, and expression of postsynaptic proteins were determined by western blot using crude synaptoneurosomes of mouse mPFC as previously reported $[11,25,28]$. Total levels of the respective protein or GAPDH (Cell Signaling \#5174, 1:1000) were used for loading control. Immunoreactivity was normalized to vehicletreated control group values for each protein.

\section{Electrophysiology}

Brain slices were prepared as previously described [25, 29]. Pyramidal neurons in layer $V$ of coronal slices of the mPFC $(400 \mu \mathrm{m})$ were visualized by videomicroscopy and whole-cell recordings were performed with an Axoclamp-2B amplifier (Axon Instruments). Neurobiotin (0.3\%) was added to the pipette solution to mark cells for later imaging. Postsynaptic currents were studied in the continuous single-electrode voltage-clamp mode $(3000 \mathrm{~Hz}$ low-pass filter) clamped at $-65 \mathrm{mV}$ to remove IPSCs from EPSCs. After completion of recording, slices were transferred to $4 \%$ paraformaldehyde $(0.1 \mathrm{M}$ phosphate buffer) and stored overnight at $4{ }^{\circ} \mathrm{C}$. Slices were then processed with streptavidin conjugated to Alexa 594 (1:1000) for visualization of labeled cells.

\section{Spine analysis}

Neurobiotin-filled mPFC layer $V$ neurons were imaged and spine density was determined as previously described [25, 29]. Images were collected on an Olympus confocal laser scanning microscope (FV3000) equipped with a $\times 60,1.42$ NA objective at a zoom of $4.65 \times$ (XY pixel dimensions $0.095 \mu \mathrm{m} \times 0.095 \mu \mathrm{m}$ ). Dendrites were sampled within the apical dendritic tuft at sites distal, midway and proximal to distal bifurcation (sampled 60,90, and $130 \mu \mathrm{m}$ from the midline, respectively), and values for spine density were expressed per um dendritic length (average dendritic segment, 40-50 $\mu \mathrm{m}$ ). Mean spine density for each sampling location as well as overall mean spine density were calculated for each labeled cell. Computerized analysis of z-stack images was performed in deconvolved confocal image stacks (AutoquantX Version 3.0.1, Media Cybernetics, Bethesda, MD) and spines were and quantified by an experimenter blinded to treatment, using NeuronStudio software [30]. 
Statistics

The results were expressed as the mean \pm standard error of mean (S.E.M.). Statistical significance was determined by a one-way analysis of variance (ANOVA) or a two-way ANOVA, followed by the Tukey's, Dunnett's or Fisher's least significant difference (LSD) multiple comparison test for comparing the treated group with the control group and multi-group comparisons as indicated in the figure legends. Statistical differences between any two groups were determined using the Student's $t$-test or Kolmogorov-Smirnov two-sample test; $P<0.05$ was used as the statistically significant cutoff as indicated in the figure legends.

\section{RESULTS}

Infusion of 8-OH-DPAT into the mPFC produces rapid and sustained antidepressant-like effects

Previous studies demonstrate that infusion of 8-OH-DPAT into the mPFC exerts antidepressant-like effects which last for $24 \mathrm{~h}$ in the FST using naive mice [20]. In this study, we further clarified the characteristics of the sustained antidepressant-like effects by mPFC infusion of 8-OH-DPAT using different types of behavioral tests, including FUST (a measure of reward-seeking behavior) and NSFT (a measure of innate anxiety in a novel area) in addition to the FST (a measure of behavioral despair). The cannula location in mPFC, cannula placements for each animal and the experimental time line are shown in Fig. 1a-c, although we did not confirm how far the agent spread. Microinjection of $8-O H$-DPAT ( 1 and $3 \mathrm{nmol} /$ side) into the MPFC significantly reduced immobility time in the FST and increased the time sniffing female urine 1 day after dosing in the $1^{\text {st }}$ FUST (Fig. $1 \mathrm{~d}: F(2,16)=12.65, p<0.001 ; 1 \mathrm{E}$ : $F(2,18)=6.036, p<0.01)$. There was a trend for increased time sniffing female urine 2 days after dosing in the $2^{\text {nd }}$ FUST (Figure S1C: $F(2,18)=2.854, p=0.0844$ ). Microinjection of $8-\mathrm{OH}$ DPAT $(3 \mathrm{nmol} / \mathrm{side})$ into the $\mathrm{mPFC}$ also significantly reduced latency to feed 3 days after dosing in the NSFT (Fig. 1f: $F(2,18)=$ $4.398, p<0.05$ ). Microinjection of $8-\mathrm{OH}$-DPAT ( 1 or $3 \mathrm{nmol} / \mathrm{side}$ ) into the mPFC had no effect on locomotor activity, time sniffing water, or home cage feeding (Figures S1A: $F(2,18)=0.7059, p=$ 0.5068 ; S1B: $F(2,18)=0.2822, p=0.7574$; S1D: $F(2,18)=1.342, p=$ 0.2864 ; S1E: $F(2,18)=0.5217, p=0.6022) .8-O H-D P A T(3 \mathrm{nmol} /$ side) also had no effect on the locomotor during the early time bins $(0-15 \mathrm{~min}$ ) of the test (Vehicle: $2649.3 \pm 319.7 ; 8-O H-D P A T$ ( $3 \mathrm{nmol} /$ side): $2212.5 \pm 82.1$ (mean \pm SEM), $n=6,8$, Student's $t$-test: $p>0.05)$.

To more rigorously test if microinjection of 8-OH-DPAT into the mPFC produces rapid antidepressant-like effects, we used a CUS model, considered one of the more valid models of depression as it provides a measure of anhedonia, a core symptom of depression, measured by intake of a sweetened solution in the SCT [31]. Moreover, it provides a test of rapid onset of action as reversal of anhedonic behavior is only observed after chronic ( 3 weeks) administration of a typical monoaminergic antidepressant $[32,33]$. CUS exposure induced depressive-like behavior in FST, SCT, and NSFT (Fig. 1j: $F(1,40)=10.47, p<0.01 ; 1 \mathrm{~K}: F(1,43)=$ $27.15, p<0.001 ; 1 \mathrm{~L}: F(1,43)=31.77, p<0.001)$. A single injection of 8-OH-DPAT ( $3 \mathrm{nmol} / \mathrm{side}$, cannula placements shown in Fig. $1 \mathrm{~h}$ ) into the mPFC significantly reduced immobility time in the FST and latency to feed in the NSFT in both the control and CUS groups (Fig. 1j: $F(1,40)=60.82, p<0.001 ; 1 \mathrm{~L}: F(1,43)=91.83, p<$ $0.001)$ at 1 and 3 days after injection, without affecting locomotor activity or home cage feeding (Figures S1F: $F(1,43)=0.1076, p=$ 0.7445 ; $\mathrm{S} 1 \mathrm{H}: F(1,43)=0.7926, p=0.3783)$. In the $\mathrm{SCT}$, conducted 2 days after microinjection of 8-OH-DPAT into the MPFC, there was a significant reversal of the effects of CUS on sucrose consumption, but no effect in the control group (Fig. $1 \mathrm{k}$ : 8 -OH-DPAT, $F(1,43)=13.46, p<0.001$; CUS, $F(1,43)=27.15, p<0.001$; interaction, $F(1,43)=14.05, p<0.001)$; there were no significant effects on total water consumption in any of the groups (Figure S1G:
$F(1,43)<0.001, p=0.9832$ ). Although there is a possibility that single housing has the effect on the behaviors, single housing did not affect the effects of 8-OH-DPAT.

Antidepressant-like effects of mPFC 8-OH-DPAT require AMPA receptor activation and $\mathrm{BDNF}$

AMPA receptor activation is required for the antidepressant-like effects of ketamine as well as other rapid-acting agents $[11,22,34,35]$, and here the requirement for AMPA receptors in the actions of 8-OH-DPAT were tested by pretreatment with NBQX, an AMPA receptor antagonist. The results demonstrate that the antidepressant-like effects of intra-mPFC injection of $8-\mathrm{OH}$ DPAT ( $3 \mathrm{nmol} / \mathrm{side}$, cannula placements shown in Fig. $2 \mathrm{~b}$ ) in the FST and NSFT were completely blocked by microinjection of NBQX $(0.03 \mathrm{nmol} / \mathrm{side}$ ) into the mPFC (Fig. $2 \mathrm{~d}$ : $8-\mathrm{OH}-\mathrm{DPAT}, F(1,28)=$ $4.422, p<0.05$; NBQX, $F(1,28)=6.593, p<0.05$; interaction, $F(1,28)$ $=4.61 p<0.05$; 2 F: 8-OH-DPAT, $F(1,28)=11.86, p<0.01$; NBQX, $F(1,28)=2.78, p=0.1066$; interaction, $F(1,28)=10.4, p<0.01)$. 8OH-DPAT and NBQX did not affect locomotor activity or food consumption (Fig. 2e: $F(1,28)=0.02119, p=0.8853$; NBQX, $F(1,28)=0.05995, p=0.8084$; S2A: 8-OH-DPAT, $F(1,28)=0.05983$, $p=0.8085 ; \mathrm{NBQX}, F(1,28)=0.05983, p=0.8085)$, and NBQX alone did not affect immobility time or latency to feed (Fig. 2d, f).

Previous studies also demonstrate that several different types of rapid-acting antidepressant, including ketamine, $(2 R, 6 R)$-hydroxynorketamine, and scopolamine require BDNF signaling to exert fast antidepressant-like actions [10, 12, 25, 36-39]. Here the role of BDNF in the actions of 8-OH-DPAT were tested by infusion of an anti-BDNF $n A B$ into the $\mathrm{mPFC}$. The antidepressant-like effects of intra-mPFC infusion of $8-\mathrm{OH}$-DPAT $(3 \mathrm{nmol} / \mathrm{side}$, cannula placements shown in Fig. $3 \mathrm{~b}$ ) in the FST and NSFT were completely blocked by microinjection of an anti-BDNF $\mathrm{nAB}(0.2 \mu \mathrm{g} / \mathrm{side})$ into the mPFC (Fig. 3d: 8-OH-DPAT, $F(1,28)=10.81, p<0.01$; BDNF nAB, $F(1,28)=14.52, p<0.001$; interaction, $F(1,28)=13.5, p<0.013 \mathrm{~F}: 8$ OH-DPAT, $F(1,28)=8.207, p<0.01$; BDNF nAB, $F(1,28)=4.692, p<$ 0.05 ; interaction, $F(1,28)=18.72, p<0.001$ ). Infusions of $8-\mathrm{OH}$ DPAT or anti-BDNF nAB did not affect locomotor activity or home cage feeding (Fig. 3e: 8-OH-DPAT, $F(1,28)=0.8039, p=0.3776$; BDNF nAB, $F(1,28)=0.01146, p=0.9155$; S2B: 8-OH-DPAT, $F(1,28)$ $=0.01382, p=0.9072 ; \mathrm{NBQX}, F(1,28)=0.3209, p=0.5756)$, and anti-BDNF $\mathrm{nAB}$ alone did not affect immobility time or latency to feed (Fig. 3d, f).

8-OH-DPAT infusion activates ERK and mTORC1 signaling in the mPFC

There are several downstream signaling pathways that are activated by BDNF, including ERK and mTORC1 that are involved in activity-dependent synaptic plasticity $[9,11,13,22,28]$. Here we examined the effects of microinjection of $8-O H-D P A T ~(3 \mathrm{nmol} /$ side) into the mPFC on levels of phosphorylated ERK and MTOR, as well as 4EBP1 and p70S6 kinase, which are downstream of mTORC1 signaling. The $\mathrm{mPFC}$ was dissected $30 \mathrm{~min}$ after microinjection of 8-OH-DPAT into the MPFC (Fig. 4a) and phosphoprotein levels were determined by western blot. Microinjection of 8-OH-DPAT into the MPFC significantly increased levels of phospho-ERK, phospho-mTOR, phospho-p70S6K, and phospho-4EBP1 in synaptoneurosomes of mPFC (Fig. 4b: $p<0.05$ ).

8-OH-DPAT infusion increases synaptic protein levels and synaptic function in the MPFC

Rapid-acting antidepressants are also reported to rapidly increase synaptic protein levels and synaptic function in the $\mathrm{MPFC}$, in part via stimulation of BDNF-mTORC1 signaling $[11,25,29,33,35,40]$. Layer $\mathrm{V}$ in the MPFC has been reported to play a key role in the antidepressant effects of ketamine [11]. Moreover, brain imaging and postmortem studies implicate the mPFC in both the pathophysiology and treatment of depression [11, 41-43]. Here, we examined the influence of 8-OH-DPAT on levels of synaptic 
A

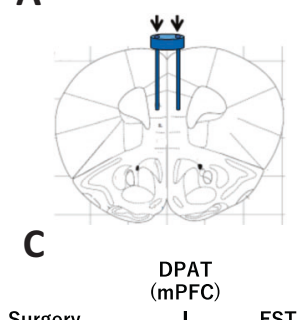

B O Veh, $\times$ DPAT1, $\triangle$ DPAT3

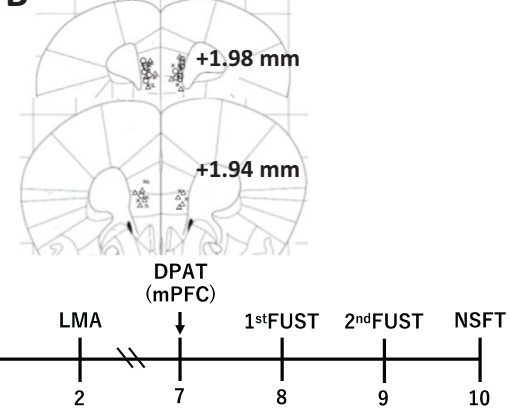

D

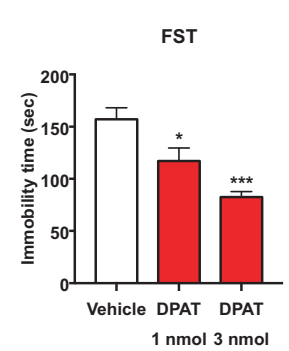

E

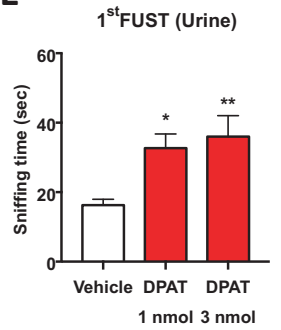

F

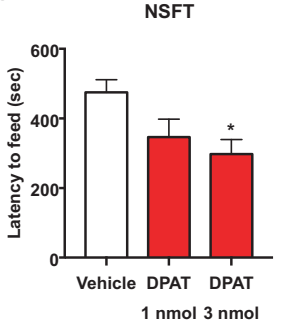

G

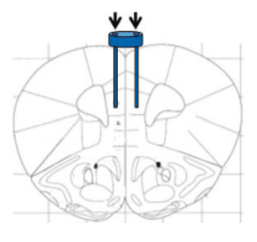

H O CON/Veh, $x$ CON/DPAT, $\triangle$ CUS/Veh, $\square$ CUS/DPAT

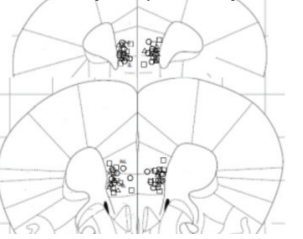

I
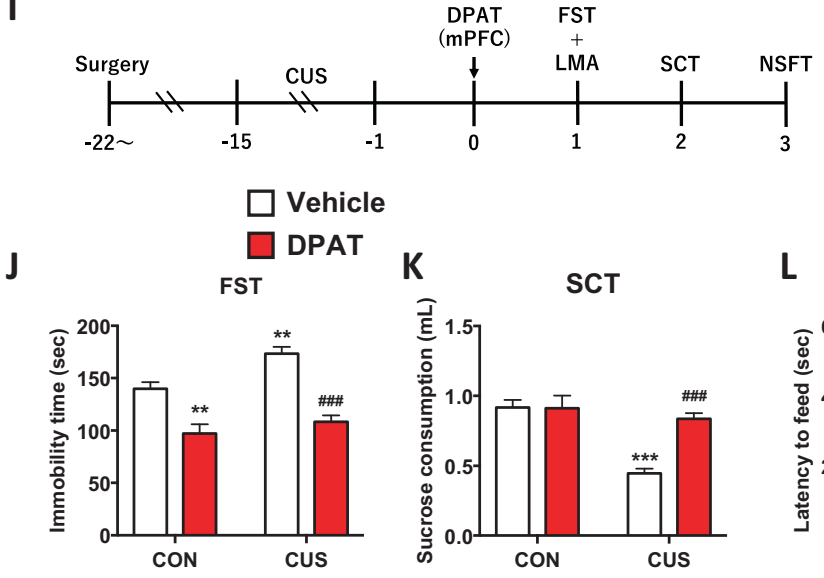

K

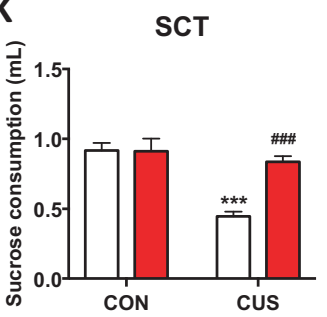

L

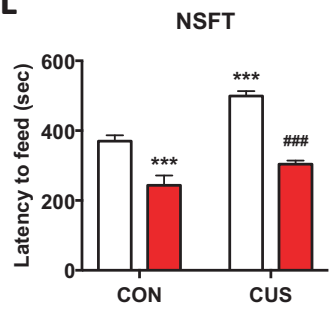

Fig. 1 Infusion of 8-OH-DPAT into the mPFC produces antidepressant-like actions in both unstressed and CUS exposed mice. a-f Mice were cannulated and after recovery received bilateral infusions of vehicle or $8-O H-D P A T ~(1,3 \mathrm{nmol} / \mathrm{side})$, or $\mathbf{g}-\mathrm{I}$ were exposed to CUS, and then received infusions of 8-OH-DPAT followed by behavioral testing. a-c Location of cannula placement in the mPFC, cannula placements for each animal and experimental time line. d Behavioral testing was conducted $24 \mathrm{~h}$ after infusions in the FST (d) and 2 days later in the LMA (Figure S1A). e, $f$ Mice received a second bilateral infusion of $8-\mathrm{OH}$-DPAT $(1,3 \mathrm{nmol} / \mathrm{side})$ into the $\mathrm{mPFC}$ and $24 \mathrm{~h}$ later were tested in the $1^{\text {st }}$ FUST $(\mathbf{e}), 2$ days later in the $2^{\text {nd }}$ FUST (Figure S1C), and 3 days later in the NSFT (f). Bars represent mean \pm SEM $((\mathbf{d}): n=4-8,(\mathbf{e}): n=7$, (f): $n=7) .{ }^{* *} P<0.001,{ }^{* *} P<0.01,{ }^{*} P<0.05$ compared with vehicle group, Dunnett's multiple comparison test, following significant results of one-way ANOVA. g-i Location of cannula placement in the MPFC, cannula placements for each animal and experimental time line. Cannulated mice were exposed to CUS for 14 days, and then received bilateral infusions of vehicle or 8-OH-DPAT $(1,3 \mathrm{nmol} / \mathrm{side}) 24 \mathrm{~h}$ after the last stress exposure. j-I Behavioral testing was conducted in the FST (j) and LMA (Figure S1F) $24 \mathrm{~h}$ after 8-OH-DPAT infusions, 2 days later in the SCT (k), and 3 days later in the NSFT (I). Bars represent mean \pm SEM ((j): $n=8-13,(\mathbf{k}): n=8-14,(\mathbf{I}): n=8-14)$. ${ }^{* * *} P<0.001,{ }^{* *} P<0.01$ compared with vehicle-treated CON group, \#\#\# $P<0.001$ compared with vehicle-treated CUS group, Tukey's multiple comparison test, following significant results of two-way ANOVA [(j-I); (j): interaction, $F(1,40)=2.569, p=0.1168$; $(\mathbf{l})$ : interaction, $F(1,43)=4.172, p<0.05]$. Vehicle $=$ saline, DPAT $=$ 8 -OH-DPAT, CON = control, CUS $=$ chronic unpredictable stress. 
A

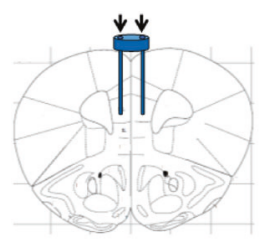

C

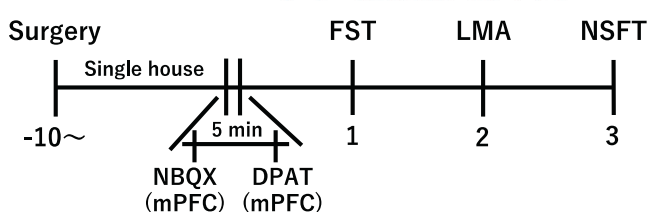

Vehicle

D

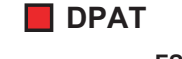

FST

$\mathbf{E}$

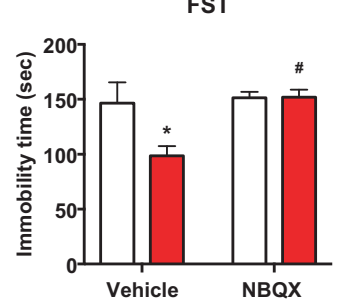

O Veh/Veh, $\times$ NBQX/DPAT,

B $\triangle$ Veh/Veh, $\square$ NBQX/DPAT

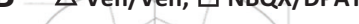

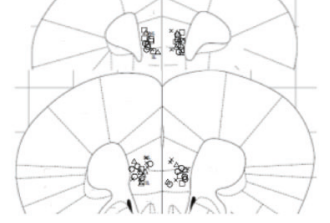

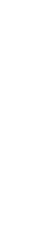

F

$\mathbf{F}$

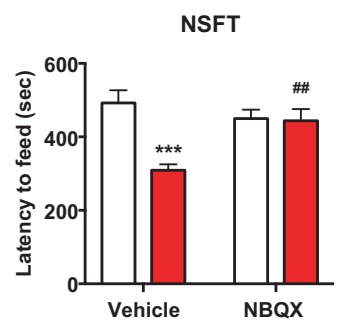

Fig. 2 Pretreatment with an AMPA receptor antagonist blocks the antidepressant-like actions of mPFC-infused 8-OH-DPAT. a-c Location of cannula placement in the MPFC, cannula placements for each animal and experimental time line. Mice received bilateral infusions of NBQX $(0.03 \mathrm{nmol} / \mathrm{side}) 5 \mathrm{~min}$ prior to microinjection of 8-OH-DPAT ( $3 \mathrm{nmol} / \mathrm{side})$, both into the mPFC. d-f Behavioral testing was conducted in the FST $24 \mathrm{~h}$ after $8-\mathrm{OH}-\mathrm{DPAT}$ infusions (d), 2 days later to the LMA test (e), and 3 days later in the NSFT (f). Bars represent mean \pm SEM; $(\mathbf{d}): n=8$, (e): $n=8$, (f): $n=8$. ${ }^{* *} P<0.001,{ }^{*} P<0.05$ compared with vehicle-treated vehicle group, ${ }^{\# \#} P<0.01$, ${ }^{*} P<0.05$ compared with vehicle-treated 8-OH-DPAT group, Tukey's multiple comparison test, following significant results of two-way ANOVA $[(\mathbf{d}-\mathbf{f}) ;(\mathbf{e})$ : interaction, $F(1,28)=0.6287$, $p=0.4345]$. Vehicle $=$ saline, DPAT $=8-\mathrm{OH}$-DPAT.

proteins as well as synaptic function in mPFC layer V. Microinjection of $8-\mathrm{OH}$-DPAT $(3 \mathrm{nmol} / \mathrm{side})$ into the $\mathrm{mPFC}$ significantly increased levels of the synaptic proteins synapsin 1 and PSD95, but not GluR1 in mPFC, measured $24 \mathrm{~h}$ after dosing (Fig. 4c: $p<$ 0.05 ; S3B). In contrast, systemic administration of 8-OH-DPAT ( $3 \mathrm{mg} / \mathrm{kg}$, s.c.) had no effect on the synaptic protein levels in the mPFC (Fig. 4d, e).

The ability of $8-\mathrm{OH}-\mathrm{DPAT}$ to activate BDNF/mTORC1 signaling and to increase synaptic protein levels suggests that microinjection of 8-OH-DPAT into the mPFC could also increase synaptic function. We have previously demonstrated that ketamine and other rapid and long-lasting antidepressant agents increase synaptic function in layer $\mathrm{V}$ pyramidal neurons in the mPFC $[11,25,29,33,35]$. In the present study, we found that microinjection of 8 -OH-DPAT $(3 \mathrm{nmol} / \mathrm{side})$ into the $\mathrm{mPFC}$ significantly increased the frequency of hypocretin-induced EPSCs in layer V pyramidal neurons in the mPFC $24 \mathrm{~h}$ after infusion, which may be involved in the antidepressant effects of ketamine [11], and produced a trend for increased basal and 5-HT-induced EPSC frequency (Fig. 5a, b: hypocretin, $p<0.05 ; 5-\mathrm{HT}, p<0.1$ ). Infusion of 8-OH-DPAT into the MPFC also significantly increased the amplitude of 5-HT-induced EPSCs (Fig. 5c: 5-HT, $p<0.05$ ). We also examined 5-HT-induced outward currents in layer $V$ pyramidal neurons and found a significant reduction in response to 8-OH-DPAT mPFC infusion (Figures S4B, C: $p<0.01$ ).

The influence of 8-OH-DPAT infusion on spine density and morphology in the mPFC was also examined. Layer $\mathrm{V}$ pyramidal neurons were filled with neurobiotin during patch clamp recording so that dendrites and spines can be visualized by confocal microscopy for analysis of changes in spine density and morphology (Fig. 5d). The results demonstrate that microinjection of 8-OH-DPAT into the mPFC significantly increased spine head diameter, a measure of mature spines (Fig. 5 e: $p<0.0001$ ) but had no effect on spine density or on different spine subtypes, including stubby, thin, or mushroom spines (Figure S5).

\section{DISCUSSION}

The results of the present study demonstrate that infusion of 8$\mathrm{OH}$-DPAT, a selective $5-\mathrm{HT}_{1 \mathrm{~A}}$ receptor agonist, into the $\mathrm{mPFC}$ exerts rapid and long-lasting antidepressant-like effects in multiple behavioral tests, including those after CUS exposure. In addition, the results show that the antidepressant-like actions of mPFC-infused 8-OH-DPAT are blocked by preinfusion of an AMPA receptor antagonist or an anti-BDNF nAb into the mPFC. The results also show that $8-\mathrm{OH}-\mathrm{DPAT}$ infusions increase levels of synaptic proteins as well as synaptic function in the mPFC. Together, these findings demonstrate that selective stimulation of the $5-\mathrm{HT}_{1 \mathrm{~A}}$ receptor in the mPFC is an effective approach to produce ketamine-like rapid synaptic and antidepressant-like behavioral responses.

Studies of $5-\mathrm{HT}_{1 \mathrm{~A}}$ receptors have utilized $8-\mathrm{OH}-\mathrm{DPAT}$, which has 60 -fold selectivity for the $5-\mathrm{HT}_{1 \mathrm{~A}}$ receptor over other 5 - $\mathrm{HT}$ receptor subtypes, and even greater selectivity relative to other classes of monoamine receptors [21]. The results demonstrate that $8-\mathrm{OH}-$ DPAT infusions into the MPFC of non-stressed mice resulted in long-lasting antidepressant-like effects in the FST similar to ketamine, consistent with our previous report [20]. These findings were extended to examination of other behaviors in naive mice, demonstrating that mPFC 8-OH-DPAT infusions produce antidepressant-like actions in the FUST, a measure of motivation and reward, and the NSFT, a measure of anxiety that is responsive to chronic but not acute administration of a typical monoaminergic antidepressant-like. The results also show that $8-O H-D P A T$ produces antidepressant-like actions in a CUS model, considered one of the more valid models of depression as CUS exposure 
A

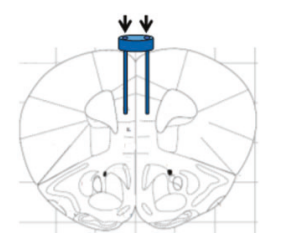

B

Veh/Veh, $\times$ nAB/DPAT $\triangle$ Veh/Veh, $\square$ nAB/DPAT

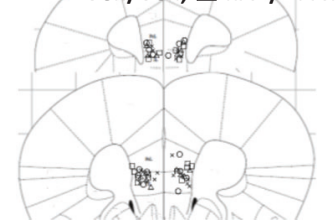

C Surgery

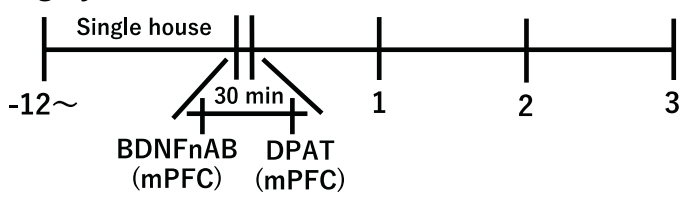

Vehicle

DPAT

D

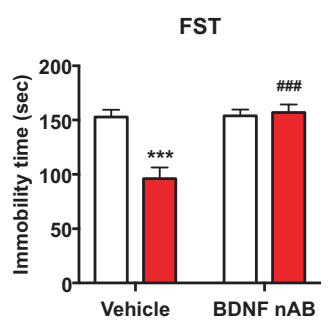

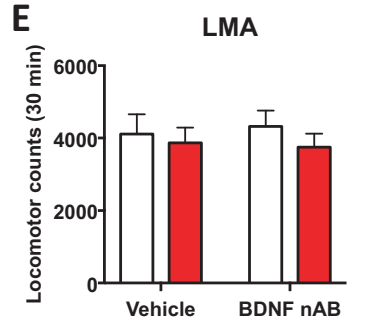

$\mathbf{F}$

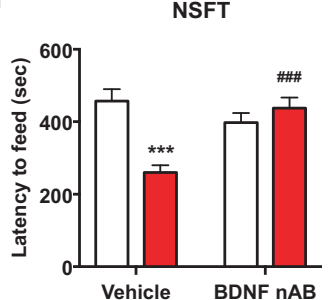

Fig. 3 Pretreatment with an anti-BDNF nAB blocks the antidepressant-like actions of mPFC-infused 8-OH-DPAT. a-c Location of cannula placement in the $\mathrm{MPFC}$, cannula placements for each animal and experimental time line. Mice received bilateral infusions of anti-BDNF nAB $(0.2 \mu \mathrm{g} / \mathrm{side}) 30 \mathrm{~min}$ prior to microinjection of 8-OH-DPAT $(3 \mathrm{nmol} / \mathrm{side})$, both into the $\mathrm{mPFC}$. $\mathbf{d}$-f Behavioral testing was conducted in the FST $24 \mathrm{~h}$ after 8-OH-DPAT infusions (d), 2 days later to the LMA test (e), and 3 days later in the NSFT (f). Bars represent mean \pm SEM; $(\mathbf{d}): n=7-9,(\mathbf{e})$ : $n=7-9,(\mathbf{f}): n=7-9$. ${ }^{* * *} P<0.001$ compared with vehicle-treated vehicle group, ${ }^{\# \# \#} P<0.001$ compared with vehicle-treated $8-O H-D P A T$ group, Tukey's multiple comparison test, following significant results of two-way ANOVA $[(\mathbf{d}-\mathbf{f})(\mathbf{e})$ : interaction, $F(1,28)=0.1282, p=0.7229]$. Vehicle $=$ saline, DPAT $=8-\mathrm{OH}-\mathrm{DPAT}$, BDNF nAB $=$ anti-BDNF nAB.

results in anhedonia, a core symptom of depression that is reversed by antidepressant-like treatments [31, 33]. Because anhedonia is reversed by chronic (3 weeks), but not acute administration of a typical monoaminergic antidepressant, the CUS model provides a rigorous test for putative rapid-acting agents [44]. A single mPFC infusion of 8-OH-DPAT resulted in significant antidepressant-like effects within 1 day and up to 3 days in the FST, SCT, and NSFT. Although stress induced by FST may affect later other behavioral tests, the antidepressant-like effects of 8-OH-DPAT are replicated, suggesting that the stress induced by FST did not affect the effects of 8-OH-DPAT. These findings indicate that selective stimulation of $5-\mathrm{HT}_{1 \mathrm{~A}}$ receptors in the MPFC improves behavioral despair, as well as anhedonia, motivation, reward, and anxiety more rapidly than conventional antidepressants. These results, together with our previous report that the sustained antidepressant-like effects of ketamine are attenuated by blockade of the $\mathrm{mPFC} 5-\mathrm{HT}_{1 \mathrm{~A}}$ receptor, indicate that selective stimulation of $5-\mathrm{HT}_{1 \mathrm{~A}}$ receptors in the mPFC plays a key role in mediating rapid, as well as long-lasting antidepressant effects, although studies of additional areas, including the hippocampus and amygdala are needed to further characterize the regional effects of 8-OH-DPAT.

The importance of the postsynaptic 5- $\mathrm{HT}_{1 \mathrm{~A}}$ receptor is supported by previous studies demonstrating that systemic administration of F15599, a selective or biased postsynaptic 5$\mathrm{HT}_{1 \mathrm{~A}}$ receptor agonist, induces more potent and sustained antidepressant-like effects than systemic administration of 5 $\mathrm{HT}_{1 \mathrm{~A}}$ receptor agonists acting on both pre- and postsynaptic sites $[23,45,46]$. The results are also consistent with a previous report demonstrating that overexpression of postsynaptic $5-\mathrm{HT}_{1 \mathrm{~A}}$ receptors in corticolimbic areas produces antidepressant-like effects and are associated with the antidepressant-like response to SSRI administration [47]. There are also several lines of evidence indicating an important role for $\mathrm{mPFC} 5-\mathrm{HT}_{1 \mathrm{~A}}$ receptors in the pathophysiology of depression. Decreased levels of $5-\mathrm{HT}_{1 \mathrm{~A}}$ receptor protein [48] and receptor ligand binding levels [49, 50] have been reported in the PFC of postmortem MDD subjects; decreased $5-\mathrm{HT}_{1 \mathrm{~A}}$ receptor protein and binding are also reported in depressed cynomolgus monkeys and rodent models [51-53]. In addition, depletion of $5-\mathrm{HT}_{1 \mathrm{~A}}$ heteroreceptors in the mPFC of adolescence rodents induces a depression-like behavioral phenotype [54]. Collectively, these findings indicate that reduced levels of $5-\mathrm{HT}_{1 \mathrm{~A}}$ receptors in the mPFC contribute to the pathophysiology of depression and that agonists that are selective for the postsynaptic $5-\mathrm{HT}_{1 \mathrm{~A}}$ receptor produce rapid-acting antidepressant-like actions.

Previous studies have demonstrated that the rapid antidepressant-like actions of ketamine and other fast acting agents require AMPA receptor stimulation and BDNF signaling $[12,20,29,36-39]$. AMPA receptor activation in response to ketamine is thought to be mediated by blockade of NMDA receptors on GABA interneurons and disinhibition of glutamate signaling $[40,55,56]$. This leads to activity-dependent release of BDNF and stimulation of downstream pathways, including ERK, as well as mTORC1 signaling [40, 55-58]. Here we show that the antidepressant-like actions of 8-OH-DPAT are also blocked by mPFC infusion of an AMPA receptor antagonist or by infusion of an anti-BDNF function-blocking antibody which attenuates the BDNF downstream signaling [59], suggesting common convergent signals for 8-OH-DPAT and ketamine. We have also reported that AMPA receptor activation mediates ketamine-stimulated BDNF release in primary cortical neurons [28]. Previous studies also demonstrate a role of $5-\mathrm{HT}_{1 \mathrm{~A}}$ receptors in the regulation of BDNF, reporting that BDNF expression is decreased when $5-\mathrm{HT}_{1 \mathrm{~A}}$ 
A
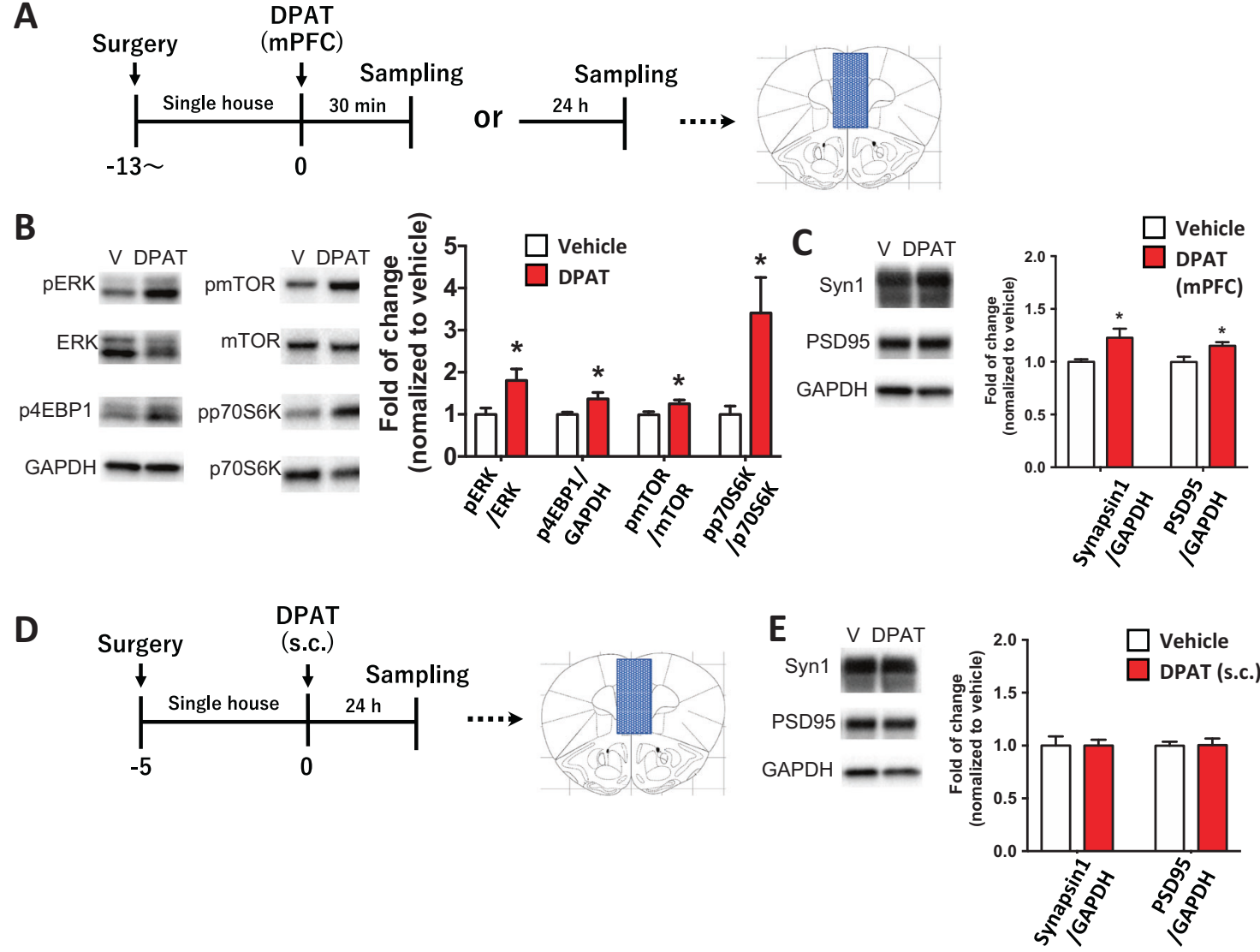

Fig. 4 Effect of 8-OH-DPAT on downstream of mTORC1 signaling and synaptic proteins in the mPFC. a Mice received bilateral infusions of 8-OH-DPAT into the mPFC, and 30 min later mPFC was dissected for analysis of phosphoproteins (b) or $24 \mathrm{~h}$ later for analysis of synaptic proteins (c). Levels of phosphorylated ERK, 4EBP1, mTOR, and p70S6K, and levels of synapsin 1 and PSD95 were determined by western blot analysis. b Representative images are shown, and density of bands was quantified. The phosphorylation levels of ERK, 4EBP1, mTOR, or p70S6K are presented as a ratio, divided by total ERK, GAPDH, total mTOR, or total p70S6K. c Representative images of synaptic protein western blots are shown. Levels of synapsin 1 and PSD95 are presented as a ratio, divided by GAPDH. $\mathbf{d}$ For comparison with mPFC infusions, mice received systemic administration of $8-\mathrm{OH}-\mathrm{DPAT}$ ( $3 \mathrm{mg} / \mathrm{kg}$, s.c.), and $\mathrm{mPFC}$ dissections were collected $24 \mathrm{~h}$ later. e Representative images of synaptic protein western blots are shown. The levels of Synapsin 1 and PSD95 are presented as a ratio, divided by GAPDH. Bars represent mean \pm SEM ((b): $n=7-8,(\mathbf{c}): n=8-10,(\mathbf{e}): n=3-5) .{ }^{*} P<0.05$ compared with vehicle group, Student's $t$-test. Vehicle $=$ saline, DPAT $=8-\mathrm{OH}-$ DPAT.

receptors are reduced in mouse ventral hippocampus [60], and increased in response to $5-\mathrm{HT}_{1 \mathrm{~A}}$ receptor stimulation in primary cultured neurons [61], although we need to directly examine the effect of 8-OH-DPAT on BDNF levels in the future study because the direct effect of the anti-BDNF function-blocking antibody used in this study on BDNF signaling has not been examined in the previous study [59].

The results also demonstrate that infusion of 8-OH-DPAT increases mTORC1 signaling in the MPFC. This includes increased levels of the phosphorylated and activated form of ERK, an upstream regulator of mTORC1, as well as increased levels of phospho-4EBP1 and phospho-p7056K, downstream mediators of mTORC1 signaling. These findings are consistent with a previous report demonstrating that the selective $5-\mathrm{HT}_{1 \mathrm{~A}}$ heteroreceptor agonist F15599 increases levels of phospho-ERK in cultured cells and in rat PFC [24]. A link between AMPA receptors and mTORC1 signaling is provided by evidence that pretreatment with an AMPA receptor antagonist blocks ketamine stimulation of ERK and mTORC1 signaling in rat PFC [11]. In addition, we have reported that the rapid antidepressant-like actions of ketamine and other fast acting agents require mTORC1 signaling $[11,25,29,35]$. Moreover, we have found that the antidepressant-like actions of MPFC 8-OH-DPAT are blocked by infusion of a selective mTORC1 inhibitor into the mPFC [20]. Together these findings suggest a functional link between the antidepressant-like actions of postsynaptic $5-\mathrm{HT}_{1 \mathrm{~A}}$ receptors and stimulation AMPA receptors, BDNF release, and mTORC1 signaling. It should be noted that the mechanisms were examined by using only naive mice in the present study. Therefore, it is necessary to examine the mechanisms of antidepressant-like effects of $8-\mathrm{OH}$ DPAT in the pathological condition.

Previous studies report that rapid and long-lasting antidepressants, including ketamine increase levels of synaptic proteins as well as synaptic function in layer $\mathrm{V}$ pyramidal neurons in the $\mathrm{mPFC}$ $[11,25,62,63]$. The results of the current study demonstrate that mPFC 8-OH-DPAT infusions increase levels of the synaptic proteins PSD95 and synapsin 1, and also increase 5-HT- and hypocretininduced EPSCs mediated by apically targeted corticocortical and thalamocortical inputs, respectively, onto $\mathrm{mPFC}$ layer $\mathrm{V}$ pyramidal neuron dendrites. There was also an increase in spine head diameter, a measure of mature spines, on layer $V$ apical dendrites. There were no effects on levels of the synaptic protein GluA1 or spine density of layer $V$ apical dendrites, which differs from the effects of ketamine and scopolamine, which increase GluA1 and spine density $[11,35]$, Notably, the putative rapid-acting antidepressant $(2 R, 6 R)$-hydroxynorketamine, like 8-OH-DPAT, increased synaptic function but not spine density of mPFC layer $\mathrm{V}$ pyramidal neurons [25]. These findings provide another convergent link for $5-\mathrm{HT}_{1 \mathrm{~A}}$ heteroreceptor agonists and other rapid-acting agents, albeit with some differences. It should also be 
A
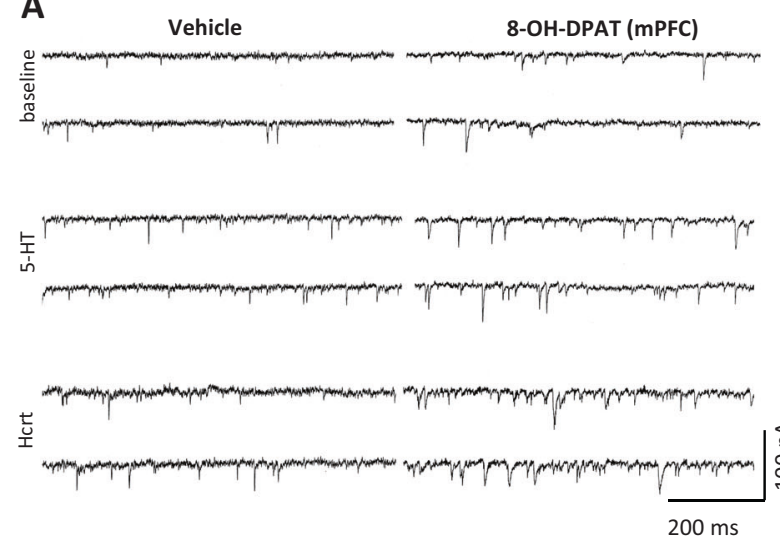

D

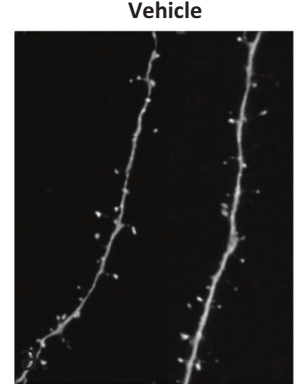

8-OH-DPAT

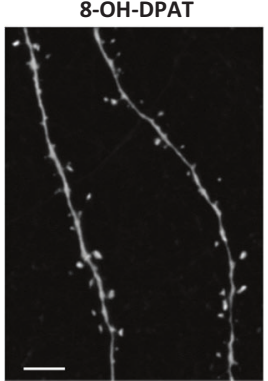

E

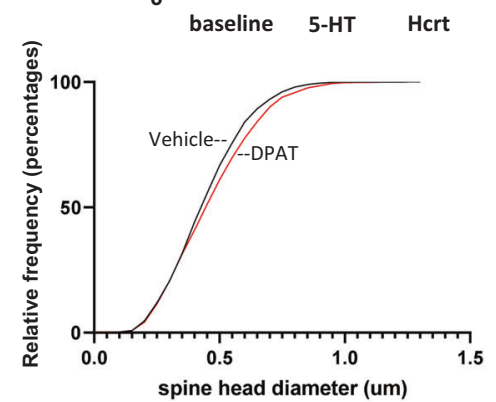

Fig. 5 Influence of 8-OH-DPAT infusions into the MPFC on synaptic function in layer $\mathbf{V}$ pyramidal neurons. Mice received bilateral infusions of $8-\mathrm{OH}$-DPAT $(3 \mathrm{nmol} / \mathrm{side}$ ) into the mPFC $24 \mathrm{~h}$ prior to slice preparation and electrophysiological recordings. Layer $\mathrm{V}$ pyramidal neurons were patched and 5-HT- or hypocretin-induced EPSCs were determined. a Representative traces of EPSC recordings from vehicle- and 8-OH-DPAT-infused mice. b EPSC frequencies are shown as the mean \pm SEM, $n=15-19$ cells from six mice. c EPSC amplitudes are mean \pm SEM, $n=15-19$ cells from six mice. ${ }^{*} P<0.05$ compared with vehicle group, Student's $t$-test. Vehicle $=$ saline, DPAT $=8$-OH-DPAT, Hcrt $=$ hypocretin. d, e During patch clamp recording cells were filled with neurobiotin and then slices were fixed and spine morphology was determined by confocal microscopy. d Representative images of neurobiotin-labeled dendrites are shown. e Infusion of 8-OH-DPAT increased spine head diameter as shown by a shift to the right in the cumulative fraction curves (Kolmogorov-Smirnov two-sample test, $D=0.064, P<0.0001$ ).

mentioned that these molecular alterations are just correlates and the causal role of these alterations in the antidepressant-like effects of 8-OH-DPAT needs to be demonstrated.

The mechanisms underlying the antidepressant-like effects of 5$\mathrm{HT}_{1 \mathrm{~A}}$ receptor stimulation, and the requirement for AMPA and BDNF signaling are unclear. The $5-\mathrm{HT}_{1 \mathrm{~A}}$ receptor is known to play a key inhibitory role in brain function due to its coupling with inward rectifier $\mathrm{K}^{+}$channels (outward current) [64]. A previous study also showed that iontophoresis of $8-\mathrm{OH}-\mathrm{DPAT}$ produced a current-dependent suppression of the basal firing rate of spontaneously active mPFC cells [65]. We also found that 8-OHDPAT incubation produced a hyperpolarizing outward current in layer $\mathrm{V}$ pyramidal neurons. Based on these direct actions, there are several possible mechanisms by which 8-OH-DPAT infusion could lead to enhanced synaptic function. One possibility is that $8-\mathrm{OH}$ DPAT produces an indirect effect via inhibition of GABA interneurons, similar to ketamine, leading to a burst of glutamate. This is supported by a previous study demonstrating that systemic administration of 8-OH-DPAT increases the activity of mPFC pyramidal neurons while reducing the discharge rate of fast spiking GABA interneurons [66]; moreover, the increase in pyramidal neuron activity was blocked by local application of a $\mathrm{GABA}_{A}$ receptor antagonist [66]. These findings indicate that systemic 8-OH-DPAT preferentially acts on $5-\mathrm{HT}_{1 \mathrm{~A}}$ receptors on GABAergic interneurons, resulting in disinhibition of pyramidal neurons.

Another possibility is provided by evidence that prior infusion of 8-OH-DPAT decreased the 5-HT-induced outward current mediated by $5-\mathrm{HT}_{1 \mathrm{~A}}$ receptors on pyramidal neurons, indicating that the inhibitory action of $5-\mathrm{HT}_{1 \mathrm{~A}}$ receptor stimulation is downregulated. These findings raise the possibility that $8-\mathrm{OH}-$ DPAT infusion leads to enhanced pyramidal cell excitability by desensitizing $5-\mathrm{HT}_{1 \mathrm{~A}}$ receptors on these neurons. Previous studies demonstrate that optogenetic stimulation of pyramidal neurons in the $\mathrm{mPFC}$ produces rapid and sustained ketamine-like antidepressant effects and increases the number and function of spine synapses of layer $V$ pyramidal neurons [67]. In addition, pharmacological or chemogenic silencing of mPFC neurons completely blocks the synaptic and/or behavioral effects of ketamine $[67,68]$. Taken together, the results suggest that $8-\mathrm{OH}-$ DPAT infusion produces rapid and sustained antidepressant-like effects by activating mPFC pyramidal neurons, although further studies are needed to determine if this is mediated by an indirect or direct mechanism.

The limitation of the current study is that we used only male mice in this study, while recent study reported that ketamine had different antidepressant-like effects between male and female mice, raising the possibility that the antidepressant-like effect of 8$\mathrm{OH}$-DPAT may differ between male and female mice. We need to confirm the difference by using female mice in the further studies.

In conclusion, the present findings suggest that selective activation of the $5-\mathrm{HT}_{1 \mathrm{~A}}$ receptor in the $\mathrm{mPFC}$ exerts rapid and long-lasting antidepressant-like effects via activation of AMPA receptors and BDNF-mTORC1 signaling that enhances synaptic function in the mPFC. These mechanisms are consistent with the reported mechanisms underlying the antidepressant effects of ketamine as well as other rapid-acting agents $[10-13,20,25$, $29,35]$. Moreover, the results are consistent with the hypothesis that the mPFC $5-\mathrm{HT}_{1 \mathrm{~A}}$ heteroreceptor is a potential target for the development of rapid-acting antidepressant agents. Additional 
Medial PFC AMPA receptor and BDNF signaling are required for the rapid...

studies will be needed to further elucidate the initial cellular target (i.e., GABA inhibitory neurons or glutamate excitatory neurons) in the $\mathrm{mPFC}$ of selective $5-\mathrm{HT}_{1 \mathrm{~A}}$ receptor agonists.

\section{FUNDING AND DISCLOSURE}

This work was supported by NIMH grant MH093897 and MH105910 (R.S.D.) and Taisho Pharma Co., Ltd. R.S.D. has received consulting fees from Taisho, Johnson \& Johnson, and Naurex, and grant support from Taisho, Johnson \& Johnson, Naurex, Allergan, Navitor, Lundbeck, and Lilly. S.C. is a current employee, and K.F. is a former employee of Taisho Pharma. None of the above-listed companies or funding agencies had any influence on the content of this article. M.V.F., R.-J.L., C.H.D., and X.-Y.L. have no conflicts or disclosures to report.

\section{ACKNOWLEDGEMENTS}

Dr. Duman passed away on February 1, 2020. This article is dedicated to the memory of his mentorship and scientific leadership.

\section{AUTHOR CONTRIBUTIONS}

K.F., S.C., and R.S.D. designed the study. K.F., M.V.F., R.-J.L., C.H.D., and X.-Y.L. conducted experiments, and the analyzed data. K.F., S.C., and R.S.D. interpreted the results and wrote the paper. All authors reviewed and approved the final paper.

\section{ADDITIONAL INFORMATION}

Supplementary Information accompanies this paper at (https://doi.org/10.1038/ s41386-020-0705-0)

Publisher's note Springer Nature remains neutral with regard to jurisdictional claims in published maps and institutional affiliations.

\section{REFERENCES}

1. Kessler RC, Berglund $P$, Demler $O$, Jin R, Koretz D, Merikangas $K R$, et al. The epidemiology of major depressive disorder: results from the National Comorbidity Survey Replication (NCS-R). JAMA 2003;289:3095-105.

2. Mueller TI, Leon AC, Keller MB, Solomon DA, Endicott J, Coryell W, et al. Recurrence after recovery from major depressive disorder during 15 years of observational follow-up. Am J Psychiatry 1999;156:1000-6.

3. Rush AJ, Trivedi MH, Wisniewski SR, Nierenberg AA, Stewart JW, Warden D, et al. Acute and longer-term outcomes in depressed outpatients requiring one or several treatment steps: a STAR*D report. Am J Psychiatry 2006;163:1905-17.

4. Aan Het Rot M, Zarate CA Jr, Charney DS, Mathew SJ. Ketamine for depression: where do we go from here? Biol Psychiatry 2012;72:537-47.

5. Berman RM, Cappiello A, Anand A, Oren DA, Heninger GR, Charney DS, et al. Antidepressant effects of ketamine in depressed patients. Biol Psychiatry 2000;47:351-4.

6. Ionescu DF, Swee MB, Pavone KJ, Taylor N, Akeju O, Baer L, et al. Rapid and sustained reductions in current suicidal ideation following repeated doses of intravenous ketamine: secondary analysis of an open-label study. J Clin Psychiatry 2016;77:e719-25.

7. Price RB, Mathew SJ. Does ketamine have anti-suicidal properties? Current status and future directions. CNS Drugs 2015;29:181-8.

8. Zarate CA Jr, Singh JB, Carlson PJ, Brutsche NE, Ameli R, Luckenbaugh DA. A randomized trial of an $\mathrm{N}$-methyl-D-aspartate antagonist in treatment-resistant major depression. Arch Gen Psychiatry 2006;63:856-64.

9. Krystal JH, Sanacora G, Duman RS. Rapid-acting glutamatergic antidepressants: the path to ketamine and beyond. Biol Psychiatry 2013;73:1133-41.

10. Koike H, Fukumoto $\mathrm{K}$, lijima M, Chaki S. Role of BDNF/TrkB signaling in antidepressant--like effects of a group II metabotropic glutamate receptor antagonist in animal models of depression. Behav Brain Res. 2013;238:48-52.

11. Li N, Lee B, Liu RJ, Banasr M, Dwyer JM, Iwata M, et al. mTOR-dependent synapse formation underlies the rapid antidepressant effects of NMDA antagonists. Science 2010;329:959-64.

12. Liu RJ, Lee FS, Li XY, Bambico F, Duman RS, Aghajanian GK. Brain-derived neurotrophic factor Val66Met allele impairs basal and ketamine- stimulated synaptogenesis in prefrontal cortex. Biol Psychiatry 2012;71:996-1005.

13. Maeng S, Zarate CA Jr, Du J, Schloesser RJ, McCammon J, Chen G, et al. Cellular mechanisms underlying the antidepressant effects of ketamine: role of alpha- amino-3-hydroxy-5-methylisoxazole-4-propionic acid receptors. Biol Psychiatry 2008;63:349-52.

14. Nishitani N, Nagayasu K, Asaoka N, Yamashiro M, Shirakawa H, Nakagawa T, et al. Raphe AMPA receptors and nicotinic acetylcholine receptors mediate ketamineinduced serotonin release in the rat prefrontal cortex. Int J Neuropsychopharmacol. 2014;17:1321-6.

15. Pham TH, Mendez-David I, Defaix C, Guiard BP, Tritschler L, David DJ, et al Ketamine treatment involves medial prefrontal cortex serotonin to induce a rapid antidepressant-like activity in $B A L B / c J$ mice. Neuropharmacology 2017; 112:198-209.

16. du Jardin KG, Liebenberg N, Müller HK, Elfving B, Sanchez C, Wegener G. Differential interaction with the serotonin system by S-ketamine, vortioxetine, and fluoxetine in a genetic rat model of depression. Psychopharmacology 2016;233:2813-25.

17. Fukumoto $K$, lijima $M$, Chaki S. Serotonin-1A receptor stimulation mediates effects of a metabotropic glutamate $2 / 3$ receptor antagonist, 2S-2-amino-2(1S,2S-2-carboxycycloprop-1-yl)-3-(xanth-9-yl)propanoic acid (LY341495), and an $\mathrm{N}$-methyl-D-aspartate receptor antagonist, ketamine, in the novelty-suppressed feeding test. Psychopharmacology 2014;231:2291-8.

18. Fukumoto $K$, lijima $M$, Chaki $S$. The antidepressant effects of an $m G l u 2 / 3$ receptor antagonist and ketamine require AMPA receptor stimulation in the MPFC and subsequent activation of the $5-\mathrm{HT}$ neurons in the DRN. Neuropsychopharmacology 2016;41:1046-56.

19. Gigliucci V, O’Dowd G, Casey S, Egan D, Gibney S, Harkin A. Ketamine elicits sustained antidepressant-like activity via a serotonin-dependent mechanism. Psychopharmacology 2013;228:157-66.

20. Fukumoto K, lijima M, Funakoshi T, Chaki S. Role of 5-HT1A receptor stimulation in the medial prefrontal cortex in the sustained antidepressant effects of ketamine. Int J Neuropsychopharmacol. 2018;21:371-81.

21. Sprouse J, Reynolds L, Li X, Braselton J, Schmidt A. 8-OH-DPAT as a 5-HT7 agonist: phase shifts of the circadian biological clock through increases in cAMP production. Neuropharmacology 2004;46:52-62.

22. Koike $\mathrm{H}$, lijima $\mathrm{M}$, Chaki S. Involvement of AMPA receptor in both the rapid and sustained antidepressant-like effects of ketamine in animal models of depression. Behav Brain Res. 2011;224:107-11.

23. Depoortère R, Papp $M$, Gruca $P$, Lason-Tyburkiewicz $M$, Niemczyk $M$, Varney MA et al. Cortical 5-hydroxytryptamine $1 \mathrm{~A}$ receptor biased agonist, NLX-101, displays rapid-acting antidepressant-like properties in the rat chronic mild stress model. J Psychopharmacol. 2019;33:1456-66.

24. Sniecikowska J, Newman-Tancredi A, Kolaczkowski M. From receptor selectivity to functional selectivity: the rise of biased agonism in 5-HT1A receptor drug discovery. Curr Top Med Chem. 2019;26:2393-420.

25. Fukumoto K, Fogaça MV, Liu RJ, Duman C, Kato T, Li XY, et al. Activity-dependent brain-derived neurotrophic factor signaling is required for the antidepressant actions of (2R,6R)-hydroxynorketamine. Proc Natl Acad Sci USA 2019;116:297-302.

26. Macbeth AH, Edds JS, Young WS. Housing conditions and stimulus females: a robust social discrimination task for studying male rodent social recognition. Nat Protoc. 2009;4:1574-81.

27. Wohleb ES, Terwilliger R, Duman CH, Duman RS. Stress-induced neuronal colony stimulating factor 1 provokes microglia-mediated neuronal remodeling and depressive-like behavior. Biol Psychiatry 2018;83:38-49.

28. Lepack AE, Bang E, Lee B, Dwyer JM, Duman RS. Fast-acting antidepressants rapidly stimulate ERK signaling and BDNF release in primary neuronal cultures. Neuropharmacology 2016;111:242-52.

29. Liu RJ, Duman C, Kato T, Hare B, Lopresto D, Bang E, et al. GLYX-13 produces rapid antidepressant responses with key synaptic and behavioral effects distinct from ketamine. Neuropsychopharmacology 2017;42:1231-42.

30. Rodriguez A, Ehlenberger DB, Dickstein DL, Hof PR, Wearne SL. Automated threedimensional detection and shape classification of dendritic spines from fluorescence microscopy images. PLoS ONE. 2008;3:e1997.

31. Willner P, Towell A, Sampson D, Sophokleous S, Muscat R. Reduction of sucrose preference by chronic unpredictable mild stress, and its restoration by a tricyclic antidepressant. Psychopharmacology 1987;93:358-64.

32. Burgdorf J, Kroes RA, Zhang XL, Gross AL, Schmidt M, Weiss C, et al. Rapastinel (GLYX-13) has therapeutic potential for the treatment of post-traumatic stress disorder: Characterization of a NMDA receptor-mediated metaplasticity process in the medial prefrontal cortex of rats. Behav Brain Res. 2015;294:177-85.

33. Li N, Liu RJ, Dwyer JM, Banasr M, Lee B, Son H, et al. Glutamate N-methyl-Daspartate receptor antagonists rapidly reverse behavioral and synaptic deficits caused by chronic stress exposure. Biol Psychiatry 2011;69:754-61.

34. Burgdorf J, Zhang XL, Nicholson KL, Balster RL, Leander JD, Stanton PK, et al. GLYX-13, a NMDA receptor glycine-site functional partial agonist, induces antidepressant-like effects without ketamine-like side effects. Neuropsychopharmacology 2013;38:729-42. 
35. Voleti B, Navarria A, Liu RJ, Banasr M, Li N, Terwilliger R, et al. Scopolamine rapidly increases mammalian target of rapamycin complex 1 signaling, synaptogenesis, and antidepressant behavioral responses. Biol Psychiatry 2013;74:742-9.

36. Autry AE, Adachi M, Nosyreva E, Na ES, Los MF, Cheng PF, et al. NMDA receptor blockade at rest triggers rapid behavioural antidepressant responses. Nature 2011:475:91-5.

37. Ghosal S, Bang E, Yue W, Hare BD, Lepack AE, Girgenti MJ, et al. Activitydependent brain-derived neurotrophic factor release is required for the rapid antidepressant actions of scopolamine. Biol Psychiatry 2018;83:29-37.

38. Kato T, Fogaça MV, Deyama S, Li XY, Fukumoto K, Duman RS. BDNF release and signaling are required for the antidepressant actions of GLYX-13. Mol Psychiatry 2018;23:2007-17.

39. Lepack AE, Fuchikami M, Dwyer JM, Banasr M, Duman RS. BDNF release is required for the behavioral actions of ketamine. Int J Neuropsychopharmacol. 2014;18:pyu033.

40. Zanos P, Moaddel R, Morris PJ, Georgiou P, Fischell J, Elmer Gl, et al. NMDAR inhibition-independent antidepressant actions of ketamine metabolites. Nature 2016;533:481-6

41. Holmes A, Wellman CL. Stress-induced prefrontal reorganization and executive dysfunction in rodents. Neurosci Biobehav Rev. 2009;33:773-83.

42. Murrough JW. Ketamine as a novel antidepressant: From synapse to behavior. Clin Pharm Ther. 2012;91:303-9.

43. Price JL, Drevets WC. Neurocircuitry of mood disorders. Neuropsychopharmacology 2010;35:192-216.

44. Morais M, Santos PA, Mateus-Pinheiro A, Patrício P, Pinto L, Sousa N, et al. The effects of chronic stress on hippocampal adult neurogenesis and dendritic plasticity are reversed by selective MAO-A inhibition. J Psychopharmacol. 2014;28:1178-83.

45. Assié MB, Bardin L, Auclair AL, Carilla-Durand $E$, Depoortère $R$, Koek W, et al. F15599, a highly selective post-synaptic 5-HT(1A) receptor agonist: in-vivo profile in behavioural models of antidepressant and serotonergic activity. Int J Neuropsychopharmacol. 2010;13:1285-98.

46. Jastrzębska-Więsek M, Partyka A, Rychtyk J, Śniecikowska J, Kołaczkowski M, Wesołowska A, et al. Activity of serotonin 5-HT1A receptor biased agonists in rat: anxiolytic and antidepressant-like properties. ACS Chem Neurosci. 2018;9:1040-50.

47. Günther L, Rothe J, Rex A, Voigt JP, Millan MJ, Fink H, et al. 5-HT(1A)-receptor over-expressing mice: genotype and sex dependent responses to antidepressants in the forced swim-test. Neuropharmacology 2011;61:433-41.

48. Szewczyk B, Albert PR, Burns AM, Czesak M, Overholser JC, Jurjus GJ, et al. Gender-specific decrease in NUDR and 5-HT1A receptor proteins in the prefrontal cortex of subjects with major depressive disorder. Int J Neuropsychopharmacol. 2009;12:155-68.

49. Sargent PA, Kjaer KH, Bench CJ, Rabiner EA, Messa C, Meyer J, et al. Brain serotonin $1 \mathrm{~A}$ receptor binding measured by positron emission tomography with [11C] WAY-100635: effects of depression and antidepressant treatment. Arch Gen Psychiatry 2000;57:174-80.

50. Wang L, Zhou C, Zhu D, Wang X, Fang L, Zhong J, et al. Serotonin-1A receptor alterations in depression: a meta-analysis of molecular imaging studies. BMC Psychiatry 2016;16:319.

51. Jovanovic H, Perski A, Berglund H, Savic I. Chronic stress is linked to $5-H T(1 A)$ receptor changes and functional disintegration of the limbic networks. Neuroimage 2011;55:1178-88.

52. Kieran N, Ou XM, lyo AH. Chronic social defeat downregulates the 5-HT1A receptor but not Freud-1 or NUDR in the rat prefrontal cortex. Neurosci Lett. 2010;469:380-4.
53. Shively CA, Friedman DP, Gage HD, Bounds MC, Brown-Proctor C, Blair JB, et al. Behavioral depression and positron emissiontomography-determined serotonin $1 \mathrm{~A}$ receptor binding potential incynomolgus monkeys. Arch Gen Psychiatry 2006;63:396-403.

54. Garcia-Garcia AL, Meng Q, Canetta S, Gardier AM, Guiard BP, Kellendonk C, et al. Serotonin signaling through prefrontal cortex 5 -HT1A receptors during adolescence can determine baseline mood-related behaviors. Cell Rep. 2017;18:1144-56.

55. Duman RS, Aghajanian GK, Sanacora G, Krystal JH. Synaptic plasticity and depression: new insights from stress and rapid-acting antidepressants. Nat Med. 2016;22:238-49.

56. Duman RS, Sanacora G, Krystal JH. Altered connectivity in depression: GABA and glutamate neurotransmitter deficits and reversal by novel treatments. Neuron. 2019;102:75-90.

57. Jourdi H, Hsu YT, Zhou M, Qin $\mathrm{Q}$, Bi X, Baudry M. Positive AMPA receptor modulation rapidly stimulates $B D N F$ release and increases dendritic $M R N A$ translation. J Neurosci. 2009;29:8688-97.

58. Suzuki A, Murakami K, Tajima Y, Hara H, Kunugi A, Kimura H. TAK-137, an AMPA receptor potentiator with little agonistic effect, produces antidepressant-like effect without causing psychotomimetic effects in rats. Pharm Biochem Behav. 2019;183:80-6.

59. Slipczuk L, Bekinschtein $P$, Katche C, Cammarota M, Izquierdo I, Medina JH. BDNF activates mTOR to regulate GluR1 expression required for memory formation. PLOS ONE. 2009;4:e6007.

60. Wu YC, Hill RA, Klug $M$, van den Buuse $M$. Sex-specific and region-specific changes in BDNF-TrkB signalling in the hippocampus of 5-HT1A receptor and BDNF single and double mutant mice. Brain Res. 2012;1452:10-17.

61. Yoshimura Y, Ishikawa C, Kasegai H, Masuda T, Yoshikawa M, Shiga T. Roles of 5$\mathrm{HT} 1 \mathrm{~A}$ receptor in the expression of AMPA receptor and BDNF in developing mouse cortical neurons. Neurosci Res. 2017;115:13-20.

62. Liu RJ, Fuchikami M, Dwyer JM, Lepack AE, Duman RS, Aghajanian GK. GSK-3 inhibition potentiates the synaptogenic and antidepressant-like effects of subthreshold doses of ketamine. Neuropsychopharmacology 2013;38:2268-77.

63. Pham TH, Defaix $C, X u X$, Deng SX, Fabresse N, Alvarez JC, et al. Common neurotransmission recruited in (R,S)-ketamine and (2R,6R)-hydroxynorketamineinduced sustained antidepressant-like effects. Biol Psychiatry 2018;84:e3-e6.

64. Montalbano A, Corradetti R, Mlinar B. Pharmacological characterization of 5-HT1A autoreceptor-coupled girk channels in rat dorsal raphe 5-HT neurons. PLoS ONE 2015;10:e0140369.

65. Ashby CR Jr, Edwards E, Wang RY. Electrophysiological evidence for a functional interaction between $5-\mathrm{HT} 1 \mathrm{~A}$ and $5-\mathrm{HT} 2 \mathrm{~A}$ receptors in the rat medial prefrontal cortex: an iontophoretic study. Synapse 1994;17:173-81.

66. Lladó-Pelfort L, Santana N, Ghisi V, Artigas F, Celada P. 5-HT1A receptor agonists enhance pyramidal cell firing in prefrontal cortex through a preferential action on GABA interneurons. Cereb Cortex. 2012;22:1487-97.

67. Fuchikami M, Thomas A, Liu R, Wohleb ES, Land BB, DiLeone RJ, et al. Optogenetic stimulation of infralimbic PFC reproduces ketamine's rapid and sustained antidepressant actions. Proc Natl Acad Sci USA 2015;112:8106-11.

68. Hare BD, Shinohara R, Liu RJ, Pothula S, DiLeone RJ, Duman RS. Optogenetic stimulation of medial prefrontal cortex Drd1 neurons produces rapid and longlasting antidepressant effects. Nat Commun. 2019;10:223. 